\title{
FOLGA FINANCEIRA E INOVAÇÃO EMPRESARIAL NO BRASIL
}

\author{
FINANCIAL SLACK AND BUSINESS INNOVATION IN BRAZIL
}

\section{HOLGURA FINANCIERA Y INOVACIÓN EMPRESARIAL EN BRASIL}

\author{
David Ferreira Lopes Santos \\ Professor do Programa de Pós-Graduação em Administração da Unesp Jaboticabal \\ Doutor em Administração de Empresas pela Universidade Presbiteriana Mackenzie \\ E-mail: david.lopes@unesp.br \\ Matheus Moreira dos Santos Guevara \\ Assistente de Contas a Pagar na Nestlé do Brasil \\ Graduado em Administração pela Unesp Jaboticabal \\ E-mail: matheusguevara@ hotmail.com \\ Santiago Valcacer Rodrigues \\ Analista Financeiro na Agility Monitoramento \\ Mestre em Administração de Empresas pela Universidade de Fortaleza \\ E-mail: santiago.valcacer@gmail.com
}

\section{RESUMO}

Esta pesquisa analisa a influência da folga financeira no nível de investimentos em inovação empresarial no Brasil entre 2010 e 2014. O posicionamento desta pesquisa procura contribuir no melhor entendimento da relação controversa entre a estratégia baseada em folga financeira e os gastos nos recursos de inovação, por meio de um modelo exploratório. A amostra compreende as 100 maiores empresas não financeiras listadas na Bolsa de Valores de São Paulo. Os gastos relativos aos investimentos em inovação foram tomados por meio de disclosure das notas explicativas e relatórios de gestão entre os anos de 2011 a 2014. A folga financeira foi estratificada em disponível, recuperável e potencial de modo que os dados foram construídos a partir das demonstrações financeiras padronizadas de 2010 a 2013. Empregou-se a análise de regressão com dados em painel balanceado, com a técnica dos mínimos quadrados ponderados. Os resultados evidenciam que a folga financeira disponível impacta de forma significativa os investimentos em inovação e para a folga recuperável, somente, os excedentes em marketing influenciam os investimentos em inovação. A avaliação do modelo empírico traz novas evidências para o tema, em especial, para a realidade brasileira.

Palavras-Chave: Capacidade de inovar. Disponibilidade de Recursos. Indústria Brasileira.

\begin{abstract}
This research analyzes the influence of financial slack on the level of investments in business innovation in Brazil between 2010 and 2014. The positioning of this research seeks to contribute to a better understanding of the controversial relationship between the strategy based on financial slack and capital expenditure with innovation resources, by exploratory
\end{abstract}


model. The sample comprises the 100 largest non-financial companies listed in the São Paulo Stock Exchange. The innovation investments were taken by disclosure of the explicative notes and management reports between the years 2011 to 2014. The financial slack was stratified into available, recoverable and potential. The data were constructed from the Financial Reports from 2010 to 2013. The regression analysis was performed using balanced panel data with the weighted least squares technique. The results show that the available financial slack has a significant impact on investments in innovation and the recoverable financial slack partially, only the slack with marketing influence investments in innovation. The evaluation of the empirical model brings new evidence for the theme, especially for the Brazilian reality.

Keywords: Ability to innovate. Availability of Resources. Brazilian industry

\section{RESUMEN}

Esta investigación analiza la influencia de la holgura financiera en el nivel de las inversiones en innovación empresarial en Brasil entre 2010 y 2014. El posicionamiento de esta investigación busca contribuir a una mejor comprensión de la relación controvertida entre la estrategia basada en la holgura financiera y el gasto en recursos de innovación, por medio de un modelo exploratorio. La muestra comprende las 100 compañías no financieras más grandes que cotizan en la Bolsa de Valores de São Paulo. Los gastos relacionados con las inversiones en innovación se tomaron mediante la divulgación de las notas explicativas y los informes de gestión entre los años 2011 y 2014. La holgura financiera se estratificó en disponible, recuperable y potencial, de modo que los datos se elaboraron a partir de las demostraciones financieras desde 2010 hasta 2013. El análisis de regresión se realizó con datos de panel equilibrados utilizando la técnica de mínimos cuadrados ponderados. Los resultados muestran que la liquidez financiera disponible tiene un impacto significativo en las inversiones en innovación y en la holgura recuperable, solo que los excedentes en marketing influyen en las inversiones en innovación. La evaluación del modelo empírico trae nueva evidencia para el tema, especialmente para la realidad brasileña.

Palabras claves: Habilidad para innovar. Disponibilidad de recursos. La industria brasileña.

\section{INTRODUÇÃO}

A inovação tornou-se uma estratégia fundamental para proporcionar às empresas crescimento e vantagem competitiva (WANG; LUO; LIU; WEI, 2016). Nessa perspectiva, a inovação tornou-se um ativo intangível empresarial que tem como características a incerteza associada aos resultados futuros e a necessidade contínua de dispêndios de capital em razão da sua natureza processual (SANTOS; BASSO; KIMURA, 2014; GOMES; MACHADO; GIOTTO, 2009). Deste modo, a inovação precisa ser suportada por uma estrutura financeira que garanta, ao mesmo tempo, a liquidez do projeto e retorno marginal superior ao custo de captação (LEE; WU; PAO, 2014).

Nesta corrente, o tema folga financeira e inovação é particularmente interessante, tendo em vista a importância em equilibrar a necessidade particular de empresas com altos níveis de inovação e uma folga financeira acima da média para que apresentem uma maior flexibilidade na implantações de novos projetos, o que proporciona uma proteção para o risco elevado inerente às operações (DOURGEOIS, 1981). 
Evidências empíricas e a prática de mercado têm estendido essa abordagem clássica para tipologia baseada em folga: disponível, recuperável ou potencial (BRADLEY; SHEPHERD; WIKLUND, 2011; DALLABONA et al., 2013). Essa análise tornou-se importante nos estudos que envolvem folga e inovação, pois as maturidades que os projetos de inovação demandam, bem como, a condição da manutenção do investimento em períodos econômicos restritivos exigem das empresas potenciais de geração de recursos suficientes para manutenção do empreendimento e os investimentos já em curso (FRANQUESA; BRANDYBERRY, 2009; NATIVIDAD, 2013).

Desta forma, importantes estudos empíricos têm procurado entender se a folga financeira é um fator importante na decisão de investimentos em inovação nas empresas (BILLETT; GARFINKEL, 2004; BRADLEY; SHEPHERD; WIKLUND, 2011; NATIVIDAD, 2013; LEE; WU; PAO, 2014). A hipótese que permeia os estudos é que a folga financeira tem impacto positivo nos dispêndios em inovação, em geral, caracterizados pela intensidade em Pesquisa e Desenvolvimento (P\&D) (LEE; WU; PAO, 2014).

No que se refere ao processo de inovação, a folga financeira pode ter uma contribuição no desempenho da inovação, como diminuir custos adicionais com inovação e criar uma cultura de experimentos e desenvolvimento de novas tecnologias ou mercados (DANIEL et al., 2004; LAI, 2016). Entretanto, a folga também pode ser uma força negativa ao processo inovador, proporcionando aumento de riscos aos negócios e demais problemas de agência (NOHRIA; GULATI, 1996; LUNGEANU; STERN; ZAJAC, 2016).

No Brasil os estudos que envolvem a folga financeira e a inovação estão em desenvolvimento (BEUREN; STAROSKY FILHO; KRESPI, 2014) e aqueles que utilizaram métodos quantitativos propuseram uma relação entre folga e inovação inversa aos trabalhos internacionais, pois entendem que a inovação deveria influenciar a folga financeira (KUNIY; BASSO; KIMURA, 2009; CHEVARRIA; CARLIN, 2012).

A importância em estudar o tema proposto no contexto brasileiro está associada aos problemas de agência relacionados ao uso da folga financeira nos investimentos em inovação que são pouco explorados em países emergentes cujas características de governança são distintas dos países desenvolvidos, em razão da maior representatividade de empresas familiares (ASHWIN; KRISHNAN; GEORGE, 2016; CONNELLY, 2016).

Com isso, a motivação deste estudo reside nesta discussão proeminente na literatura entre folga financeira e investimentos em inovação considerando o caso brasileiro utilizando as 100 maiores empresas não financeiras listadas na B3 (Brasil, Bolsa, Balcão). Neste sentido, o objetivo principal da pesquisa é analisar a influência da folga organizacional nos investimentos em inovação nas 100 maiores empresas não financeiras listadas na B3 entre 2010 e 2014. Para tanto, buscou-se identificar as empresas cujos papéis foram os mais negociados, com ênfase nas empresas que compõe um grupo com elevado volume de negociação, especificamente, as empresas que compõe o IBrX-100, devido a sua relevância (ARAÚJO et al., 2017).Os estudos sobre folga organizacional são predominantemente relacionados com aspectos comportamental (FARIA; SILVA, 2013), no entanto, nesta pesquisa, os esforços foram dirigidos para a compreensão da influência da folga organizacional na inovação empresarial no Brasil, haja vista que de acordo com Oliveira, Dallabona e Pletsch (2018), os recursos excedentes da organização por ser aplicado de diversas formas, inclusive em inovação para gerar vantagem competitiva.

Assim, essa pesquisa se posiciona em um espaço teórico prático em construção no Brasil e com resultados no exterior controversos (SANTOS, 2010; ZONA, 2010), o que exige 
novas investigações para auxiliar não apenas na melhor compreensão do fenômeno sob o foco acadêmico, mas, também, empresarial, em função da possibilidade de trazer novas informações sobre a forma como as firmas decidem sobre os seus investimentos em inovação (ASHWIN; KRISHNAN; GEORGE, 2016).

Há, ainda, uma dificuldade em evidenciar os gastos com inovação nas demonstrações financeiras das empresas, pois não há uma conta específica nas demonstrações e em razão das múltiplas naturezas desses gastos (salários de funcionários em pesquisa e desenvolvimento, máquinas e equipamentos, licença de softwares, registro e cessão de direitos de patentes, treinamentos, entre outros) (SANTOS, BASSO, KIMURA, 2012). Esses gastos são lançados em diferentes rubricas contábeis, o que demanda evidenciação nas notas explicativas de cada conta.

Para tanto, o trabalho foi organizado com mais quatro seções subsequentes. A próxima apresenta os fundamentos teóricos que suportaram a proposição do modelo empírico. A terceira seção traz os materiais utilizados como informação para construção das variáveis e o método utilizado. A quarta seção apresenta e discute os resultados do estudo, para então na quinta seção serem abordadas as implicações atuais e futuras desta pesquisa nas considerações finais. As referências bibliográficas e apêndices encerram o trabalho.

\section{FUNDAMENTAÇÃO TEÓRICA}

O objetivo mais importante de uma organização é a maximização dos seus resultados para acionistas e credores a longo prazo (CAMPOS; NAKAMURA, 2013). Há, ainda, segundo Campos e Nakamura (2013) um objetivo secundário que é sobrevivência a curto prazo, por meio que sejam capazes de tolerar os riscos tanto da própria organização quanto de mercado.

Para que isso seja concretizado, Lintner (1956) e Campos e Nakamura (2013) dizem que seria viável que a empresa garantisse uma capacidade de gerar recursos disponíveis dentro da organização acima do que é necessário, o que pode ser chamada folga organizacional.

Quando se trata de folga organizacional, devem ser analisadas de duas maneiras: a) por ser um incentivo à consecução de oportunidades futuras; e b) por representar uma forma de desperdício, um excesso de gastos resultantes de ineficiências operacionais e gerenciais e que geram um resultado negativo para a empresa (ZONA, 2012).

"O conceito de folga é extensamente utilizado nas literaturas de teoria organizacional e estratégias empresariais, mas não há nenhuma única definição de consenso. Porém, definições sugerem a ideia de excesso de recursos que fornecem proteção e oportunidade" (MOSES, 1992, p. 42). Tal afirmação deve-se, principalmente, as pesquisas que foram desenvolvidas por (BOURGEOIS, 1981).

Bourgeois (1981) trouxe várias definições sobre folga organizacional, como nota-se no Quadro 1. Em especial, de James March (1979), que ao longo dos anos apresenta-se como um dos principais pesquisadores neste tema.

Quadro 1 - Definições de folga organizacional

\begin{tabular}{|l|l|}
\hline Autores & Definição de Folga \\
\hline $\begin{array}{l}\text { Cyert e March } \\
\text { (1963) }\end{array}$ & $\begin{array}{l}\text { "A disparidade entre os recursos disponíveis da organização e os pagamentos exigidos para } \\
\text { manter a coligação" (p. 36). Cita como exemplos: o excesso de dividendos pagos aos } \\
\text { acionistas, preços mais baixos do que o necessário para manter os compradores, salários } \\
\text { maiores que o necessário para manter o empregado, gratificações para executivos, } \\
\text { crescimento de subunidades além das taxas relativas de contribuições. Além desta lista }\end{array}$ \\
\hline
\end{tabular}


Santos, Guevara e Rodrigues (2018)

Folga Financeira e Inovação Empresarial no Brasil

\begin{tabular}{|c|c|}
\hline & $\begin{array}{l}\text { menciona: "Fornecimento de recursos desviados" (p. 54). "Recursos afunilados para a } \\
\text { satisfação dos objetivos do indivíduo e subgrupo (versus Organização)" (p. 98). }\end{array}$ \\
\hline Child (1972) & $\begin{array}{l}\text { "A margem ou excesso (desempenho que excede o nível de satisfação) que permite que a } \\
\text { coligação dominante de uma organização adote arranjos estruturais que outorgam com as } \\
\text { próprias preferências (versus. bons ajustes de ordens da teoria de contingência), mesmo com } \\
\text { alguns custos administrativos extras" (p. 11). }\end{array}$ \\
\hline $\begin{array}{l}\text { Cohen, March e } \\
\text { Olsen (1972) }\end{array}$ & $\begin{array}{l}\text { "A diferença entre os recursos da organização e da combinação de demandas feitas sobre } \\
\text { ela" (p. 12). }\end{array}$ \\
\hline $\begin{array}{l}\text { March e Olsen } \\
(1976)\end{array}$ & "A diferença entre os recursos existentes e as demandas ativadas" (p. 87). \\
\hline $\begin{array}{l}\text { Dimick e } \\
\text { Murray (1978) }\end{array}$ & $\begin{array}{l}\text { "Os recursos que uma organização tenha adquirido que não estão comprometidos com } \\
\text { despesas necessárias. Em essência, estes são recursos que podem ser utilizados de forma } \\
\text { discricionária" (p. 616). }\end{array}$ \\
\hline $\begin{array}{l}\text { Litschert e } \\
\text { Bonham (1978) }\end{array}$ & $\begin{array}{l}\text { Utilizando a definição de Cyert e March (1963), os autores ofereceram a seguinte sugestão } \\
\text { de operação: Folga = a variação da média entre as organizações comparáveis sobre: ROE, } \\
\text { ROTA, vendas líquidas, e lucro bruto com um por cento das vendas. }\end{array}$ \\
\hline March (1979) & $\begin{array}{l}\text { "Considerando que organizações não se aperfeiçoam sempre, elas acumulam recursos } \\
\text { disponíveis e oportunidades inexploradas que então se tornam um para-choque contratempos } \\
\text { ruins. Embora o para-choque necessariamente não é pretendido, a folga produz desempenho } \\
\text { suave, reduzindo o desempenho durante bons tempos e melhorando-o durante períodos de } \\
\text { tempos ruins" (citado em Stanford GSB, p. 17). }\end{array}$ \\
\hline
\end{tabular}

Fonte: (BOURGEOIS, 1981, p. 30).

Nota-se que há uma aproximação elevada entre os conceitos de folga organizacional com a dimensão financeira, em especial, quando se trata do dimensionamento desta folga, em todo modo, o excedente de recursos pode ser expresso de diferentes formas. Essa questão também pode ser observada em levantamento bibliométrico mais recente proposto por Santos (2010) no Quadro 2.

Quadro 2 - Conceitos de folga organizacional

\begin{tabular}{|c|c|}
\hline Autores & Conceito de Folga Organizacional \\
\hline Burgeois (1981) & $\begin{array}{l}\text { É aquele "colchão" de recursos efetivos ou potenciais que permitem a uma } \\
\text { organização adaptar-se com sucesso às pressões internas de ajustes ou às pressões } \\
\text { externas por mudanças em politica, assim como iniciar mudanças estratégicas com } \\
\text { respeito ao ambiente externo. }\end{array}$ \\
\hline $\begin{array}{l}\text { Sharfman, Wolf, Chase e } \\
\text { Tansik (1988) }\end{array}$ & $\begin{array}{l}\text { Compreende recursos em excesso, potencialmente recuperáveis que uma } \\
\text { organização necessita para manter suas operações normais. }\end{array}$ \\
\hline Bromiley (1991) & $\begin{array}{l}\text { É o excesso de recursos que uma empresa pode utilizar para aliviar as diferenças } \\
\text { entre mudanças no ambiente em que opera e a necessidade de respostas } \\
\text { organizacionais. }\end{array}$ \\
\hline Moses (1992) & $\begin{array}{l}\text { As definições preponderantes de folga organizacional a consideram como sendo } \\
\text { constituída de recursos possuídos pela empresa em montante superior às suas } \\
\text { necessidades para fazer frente às suas atividades. }\end{array}$ \\
\hline $\begin{array}{l}\text { Nohria e Gulati } \\
(1996,1997)\end{array}$ & $\begin{array}{l}\text { É o conjunto de recursos em uma organização que está além do mínimo necessário } \\
\text { para produzir um dado nível de produção. }\end{array}$ \\
\hline $\begin{array}{l}\text { Greenley e Oktemgil } \\
\text { (1998) }\end{array}$ & $\begin{array}{l}\text { Recursos que não foram empregados de forma ótima, mas que permitem à empresa } \\
\text { adaptar-se às mudanças no ambiente, fornecendo os meios para alcançar } \\
\text { flexibilidade no desenvolvimento de opções estratégicas de forma a buscar } \\
\text { oportunidades. O resultado de gerar e investir recursos de folga para atingir } \\
\text { flexibilidade deve ser melhorar o desempenho. Recursos de folga são mantidos como } \\
\text { um seguro contra pedras futuras potenciais. }\end{array}$ \\
\hline
\end{tabular}

Revista de Gestão, Finanças e Contabilidade - v. 8, n. 1, p. 36-55, jan./abr. 2018 ISSN 2238-5320, UNEB, Salvador/BA 
Santos, Guevara e Rodrigues (2018)

Folga Financeira e Inovação Empresarial no Brasil

\begin{tabular}{|l|l|}
\hline Lawson (2001) & $\begin{array}{l}\text { Tempo disponível, ou dinheiro para comprar este tempo, que não esteja } \\
\text { completamente engajado na entrega do produto ou serviço principal da organização. }\end{array}$ \\
\hline Tan e Peng (2003) & $\begin{array}{l}\text { Disponibilidade de recursos de uma empresa necessários para assegurar sua } \\
\text { sobrevivência no longo prazo. A folga organizacional pode ser utilizada como } \\
\text { proteção à organização e turbulências no ambiente. }\end{array}$ \\
\hline
\end{tabular}

Fonte: (SANTOS, 2010, p. 54).

No Quadro 2 é possível perceber que os recursos em folga podem estar relacionados a recursos humanos, físicos e financeiros (BEUREN; STAROSKY FILHO; KRESPI, 2014). Salienta-se que "(...) não é unânime a discussão na literatura acerca do papel da folga, ou seja, se a mesma possui influências positivas ou negativas nas organizações" (SANTOS, 2010, p.54).

Segundo Dallabona et al. (2013), existem três tipos de folga organizacional: folga disponível, recuperável e potencial. A folga disponível representa os recursos disponíveis e não empregados em objetivos específicos da empresa, já a folga recuperável tem como característica os recursos que já foram absorvidos, mas podem ser recuperados futuramente e a folga potencial é a capacidade de gerar recursos adicionais originados da organização (DALLABONA, et al., 2013). .

Campos e Nakamura (2013) ainda relatam que inseridos no conceito de folga organizacional estão os conceitos de folga financeira e liquidez. Para Campos (2011), sendo a liquidez a aptidão de a empresa transformar seus ativos de maneira rápida em recursos monetários, pode-se dizer que a folga financeira engloba a liquidez, mas conjuntamente abrange a capacidade da empresa em dispor de recursos excedentes aos seus compromissos.

Greve (2003) diz que folga financeira significa garantir recursos financeiros que não estão comprometidos em atividades específicas. Existem diversos tipos de folga financeira segundo a literatura, um exemplo é a folga não absorvida que pode ser chamada de folga disponível, que representa os recursos que não foram confirmados para operações do sistema, assim os gestores tem fácil acessos a eles (LATHAM; BRAUN, 2009). Folga absorvida são os recursos que já foram autorizados para um uso específico ou então estão atrelados a alguma operação (LEE; WU; PAO, 2014).

Lee (2015) afirma que se as empresas não possuem uma folga suficiente em momentos de crises, elas tendem a cortar ou adiar os gastos com investimentos; esta situação também é corroborada por Chakrabarti (2015) que identificou fraca capacidade de recuperação do crescimento em períodos de crise as empresas com folga financeira baixa.

Para Vanacker, Collewaert e Paeleman (2013) a folga financeira pode ser entendida com um recurso útil que esta a disposição da empresa e que suporte a organização no alcance de seus objetivos estratégicos. A folga financeira pode permitir, também, à organização a oportunidade de assumir maiores riscos em projetos de inovações e que podem aumentar a competitividade organizacional (BRADLEY; SHEPHERD; WIKLUND, 2011; ZONA, 2012; LAI, 2016).

A Teoria da Dependência de Recursos destaca que o investimento em inovação pode demandar um aumento da folga organizacional (SANGHOON, 2015; ASHWIN; KRISHNAN; GEORGE, 2016; WANG et al., 2016). A folga organizacional pode oferecer recursos para que haja inovação, segundo a teoria comportamental. Isso ocorre pelo fato dos riscos serem dimensionados pelos recursos existentes na organização; sendo assim, a presença de folga organizacional e financeira presente pode proporcionar a redução do medo de 
fracassar em inovações e um aumento nas experimentações (CYERT; MARCH, 1963; WANG et al., 2016).

Por outro lado, o excesso de recursos financeiros internos à empresa pode favorecer a decisões gerenciais precipitadas e que contribuam para a redução do valor das empresas, em especial, nas decisões que envolvem investimentos com maiores riscos (LUNGEANU; STERN; ZAJAC, 2016).

Nesta esteira, a folga financeira também pode ser compreendida como uma característica de empresas com fraco desempenho inovador, tendo em vista que, em razão dos potenciais problemas de agência inerentes a maior disponibilidade de recursos, as decisões que suportam os investimentos em inovação podem ser equivocadas (LUNGEANU; STERN; ZAJAC, 2016).

A forma como a folga se apresenta e é gerenciada pode direcionar para resultados positivos ou negativos, haja vista que é possível que a distinção entre os níveis propostos para a folga organizacional possa contribuir para um melhor entendimento dos efeitos nos investimentos em inovação ou no desempenho das empresas (ZONA, 2012; LUNGEANU; STERN; ZAJAC, 2016).

O entendimento da inovação como um recurso organizacional e que demanda um programa de investimentos descortinou uma importante discussão teórica quanto aos fatores que determinam a forma como tais investimentos são realizados (SANTOS et al., 2012; KIMURA, 2012; WANG et al., 2016).

A dificuldade na estimativa dos fluxos de caixa futuros nos investimentos em inovação se apresenta como um dos principais limites ao uso de recursos de terceiros no financiamento dos projetos, assim, as empresas buscam obter uma folga financeira maior como forma de viabilizar estratégias de inovação (SATTA et al., 2016).

Diante das pesquisas analisadas e listadas nesta seção, nota-se a ausência de um consenso teórico quanto ao impacto da folga financeira nos investimentos em inovação. Percebe-se uma corrente majoritária que sinaliza para um efeito positivo nos investimentos em inovação. No entanto, as evidências para países emergentes e, em especial, para o Brasil ainda são incipientes e propõem uma relação inversa aos principais estudos no tema, pois o pressuposto destes trabalhos é que os investimentos em inovação influenciariam os níveis de folga (KUNIY; BASSO; KIMURA, 2009; CHEVARRIA; CARLIN, 2012).

A existência dessas lacunas e dissonâncias teóricas permitem, portanto, estender as aplicações à realidade empírica por diferentes abordagem metodológicas, como também desafiam os resultados empíricos em aumentar a compreensão teórica sobre o tema.

\section{METODOLOGIA}

Em função do objetivo dessa pesquisa, optou-se por um estudo quantitativo com finalidade exploratória para a realidade brasileira. Na sequência são apresentados os materiais e posteriormente os métodos que suportaram o processo empírico da pesquisa.

\subsection{Amostra}

A B3 computou em 2014 um total de 353 empresas domésticas, sendo esta bolsa a principal instituição do mercado de capitais da América Latina. Os 100 maiores grupos econômicos presentes na bolsa formam o Índice Brasil 100 (IBrX-100) sendo esta carteira 
teórica superior ao principal índice da B3 (IBOVESPA) em quantidade de ativos e volume negociado.

Entre as 100 empresas do IBrX-100 em 2014, 15 eram conglomerados financeiros que em função da sua especificidade foram excluídos. Contou-se, então com 85 empresas não financeiras do IBrX-100 para amostra, que incorporou mais 15 empresas não financeiras listadas na B3 que apresentavam os maiores valores de ativo após as 100 empresas do IBrX100. Desta forma, o trabalho compreende as 100 maiores empresas brasileiras em valor de ativo no ano de 2014. As empresas utilizadas estão listadas no Apêndice A.

Além da representatividade econômica desta amostra, estudos recentes para a realidade brasileira demonstram que poucas empresas possuem estratégias de investimentos em inovação, sendo inclusive, restrita em empresas âncoras nos seus setores (SANTOS et al., 2014). A utilização de empresas com capital aberto neste estudo é fundamental em razão da proposta quantitativa e do modelo de análise a ser utilizado que demanda informações publicadas e com elevado grau de confiabilidade.

De acordo com Ponte e Oliveira(2004), para atender as necessidades dos usuários externos, a lei das sociedades por ação, ou seja, empresas de capital aberto, deve atender a um conjunto mínimo de governança na confecção dos relatórios contábil financeiro bem como sua divulgação.

\subsection{Construção das Variáveis}

A variável de interesse a ser explicada diz respeito à inovação, para tanto, foi utilizada como proxy aos investimentos em inovação as informações quantitativas evidenciadas nos relatórios financeiros das empresas que apontavam para os investimentos em inovação.

Assim, a variável dependente foi tomada a partir do disclosure dos dispêndios em inovação nas demonstrações financeiras padronizadas. Como não existe uma conta específica para gastos com inovação, houve a necessidade da análise individual das demonstrações financeiras, bem como a leitura das notas explicativas associadas ao balanço patrimonial e demonstração de resultados.

Observa-se que após a promulgação das Leis $\mathrm{n}^{\circ} 11.638 / 2007$ e $\mathrm{n}^{\mathrm{o}} 11.941 / 2009$ e o CPC-13 as companhias abertas precisam esclarecer de forma qualitativa as informações financeiras das demonstrações, sendo algumas obrigatórias e outras facultadas. Neste caso, em específico, as informações sobre inovação podem ser lançadas nas contas de patrimônio (Imobilizado) ou resultados (Despesas Administrativas e Comerciais), sendo que o detalhamento não é obrigatório, assim, tomaram-se, apenas, os valores que foram informados pelas empresas como dispêndios no recurso inovação, sendo considerada as variáveis que constituem o construto de inovação proposto por Santos, Basso e Kimura (2012) (Gastos com P\&D Interno e Externo, Aquisição de software e licença de patentes, Treinamento, Aquisição de Máquinas e Outros Conhecimentos); não foi possível computar os gastos com pessoal de $\mathrm{P} \& \mathrm{D}$, pois as empresas não reportam essas informações.

O total dos gastos com inovação foi relativizado pela receita da empresa no igual período, conforme Equação 1. Ressalta-se que essas informações foram tomadas para os anos de 2011, 2012, 2013 e 2014.

$$
\text { (Inova) Inovação }=\frac{\text { Gastos com Inovação }}{\text { Receita }}
$$


As variáveis associadas à folga financeira constituíram as variáveis explicativas do modelo e os dados primários para construção das séries foram retirados do Sistema Economática ${ }^{\circledR}$. Conforme os trabalhos de Geiger e Cashen (2003) as informações referentes à folga financeira foram trabalhadas com a defasagem de um ano em relação ao investimento em inovação, portanto, os resultados para estas variáveis foram computados para os anos de 2010, 2011, 2012 e 2013.

As métricas que representam a folga financeira neste trabalho são: disponível (Equações 2, 3 e 4) (GEIGER; CASHEN, 2003), (ZONA, 2012); recuperável (Equações 5, 6 e 7) (CHEVARRIA; CARLIN, 2012), (KUNIY; BASSO; KIMURA, 2009) e potencial (Equações 8, 9 e 10) (BRADLEY; SHEPHERD; WIKLUND, 2011).

(Liquidez) Liquidez Corrente $=\frac{\text { Ativo Circulante }}{\text { Passivo Circulante }}$

(Tesoura) Coeficente de efeito tesoura $=\frac{\text { Saldo de } \text { Tesouraria }}{\text { Receita Operacional }}$

(Overtrading) Coeficiente de overtrading $=\frac{\text { Capital Circulante Líquido }}{\text { Receita operacional }}$

(MA) Margem Administrativa $=\frac{\text { Despesas Administrativas }}{\text { Receita operacional }}$

(MM) Margem Mercadológica $=\frac{\text { Despesas Comerciais }}{\text { Receita operacional }}$

(Retenção) Capacidade de Retenção $=\frac{(\text { Lucro-Div })}{\text { Receita }}-\frac{\text { Div }}{P L}+\frac{(A C-P C)}{\text { Receita }}$

(CJ) Cobertura de Juros $=\frac{\text { Despesas financeiras }}{E B I T}$

(EC) Estrutura de Capital $=\frac{\text { Financiamentos de Curto e Longo Prazo }}{\text { Patrimônio Líquido }}$

(CC) Comprometimento do Caixa $=\frac{\text { EBTIDA }}{\text { Financiamentos de Curto e Longo Prazo }}$

(Log_Receita)

Em razão da característica exploratória do modelo, as séries construídas foram analisadas, inicialmente, pelo grau de associação entre elas (coeficiente de correlação), a fim de se verificar a possibilidade de agrupamento pela análise fatorial ou indicar a seleção das variáveis com fraca associação para utilização no modelo empírico.

Os procedimentos utilizados foram importantes para minimizar possíveis impactos de multicolineariedade (GUJARATI, 2006). Em adição, as séries estatísticas também foram 
analisadas levando em consideração suas características descritivas, quanto as medidas de posição, dispersão e normalidade.

\subsection{Análise de Regressão Múltipla com Dados em Painel}

No processo de regressão múltipla as variáveis explicativas (independentes) são tratadas no sentido de se verificar o peso relativo que cada independente tem para explicar a variável dependente (GUJARATI, 2006), o uso desta técnica em painel de dados permite a análise das informações considerando os cortes transversais associado com a evolução temporal, o que garante um maior volume de observações e parcimônia na análise dos coeficientes. Neste estudo, foram computados um total de 400 observações (4 anos e 100 empresas).

A função de regressão com dados em painel pode ser expressa como:

$Y_{i t}=\beta_{1}+\beta_{2} X_{2 i t}+\beta_{3} X_{3 i t}+\cdots+\beta_{j} X_{j i t}+\varepsilon_{i t}$

Onde,

$Y=$ Variável independente; $\beta_{1}=$ Intercepto $; X_{1,2,3, j}=$ Variáveis dependentes; $\beta_{1,2,3, j}=$ Coeficientes parciais da regressão e o " $\varepsilon$ " o termo de erro estocástico. Os subscritos " $i$ " e " $t$ " foram as empresas individuais em cada corte transversal durante o período analisado (2014/2013, 2013/2012, 2012/2011, 2011/2010).

Assim, a análise de regressão múltipla com painel de dados permite analisar os graus de influência das variáveis independentes (folga) na variável dependente (inovação). Em razão da folga financeira ser uma decisão discricionária de cada organização, entende-se que o modelo por efeitos fixos deve prevalecer frente à opção do aleatório, pois ele capta as diferenças entre as empresas durante o período no intercepto.

No interesse de verificar a confiabilidade do modelo proposto, os seguintes procedimentos foram executados (GUJARATI, 2006; HAIR et al., 2005):

i) Verificou-se a normalidade das séries; ii) Identificou-se possíveis observações discrepantes (outliers); iii) Analisou-se o grau de associação das variáveis (coeficiente de correlação); iv) Testes de normalidade dos resíduos $\left(\chi_{\mathrm{i}}\right)$; v) Heterocedasticidade (Teste de White); vi) Estatística $\mathrm{F}$ da regressão; vii) além do próprio $\mathrm{R}^{2}$ (coeficiente de determinação).

O software utilizado para a pesquisa foi o Gnu Regression, Econometrics and Timeseries Library (GRETL) versão 1.9.

\section{ANÁLISE DOS RESULTADOS}

As estatísticas descritivas básicas das variáveis selecionadas são apresentadas na Tabela 1.

Tabela 1 - Estatísticas Descritivas das Variáveis do Modelo Empírico

\begin{tabular}{c|c|c|c|c|c}
\hline Variável & Média & Mediana & Desv. Padrão & Mínimo & Máximo \\
\hline INOVA (\%) & 0,357 & 0,127 & 0,510 & 0,000 & 3,50 \\
\hline LIQUIDEZ & 1,67 & 1,52 & 1,05 & 0,000 & 12,1 \\
\hline TESOURA & 0,106 & 0,0666 & 1,96 & $-14,3$ & 21,8 \\
\hline OVERTRADING & 0,202 & 0,161 & 1,44 & $-18,4$ & 11,7 \\
\hline MA & 0,171 & 0,0632 & 0,709 & 0,000 & 9,09 \\
\hline MM & 0,0878 & 0,0518 & 0,292 & 0,000 & 5,69 \\
\hline RETENCAO & 0,501 & 0,376 & 18,1 & $-201,0$ & 294,0 \\
\hline CJ & 1,54 & 0,400 & 9,75 & $-10,6$ & 131,0 \\
\hline
\end{tabular}


Santos, Guevara e Rodrigues (2018)

Folga Financeira e Inovação Empresarial no Brasil

\begin{tabular}{c|c|c|c|c|c}
\hline EC & 1,07 & 0,748 & 1,66 & $-18,7$ & 11,1 \\
\hline CC & 0,662 & 0,301 & 1,85 & $-1,59$ & 18,0 \\
\hline RECEITA & 15,3 & 15,4 & 1,63 & 3,99 & 19,6 \\
\hline
\end{tabular}

Fonte: Elaborado pelos autores (2018).

Observa-se pelo desvio padrão o grau de variabilidade entre as variáveis, seja pelo resultado individual, seja pela média para a amostra. Essa situação é decorrente das diferenças significativas entre as empresas brasileiras e os distintos setores que congregam essas empresas.

A normalidade das variáveis neste tipo de estudo é sempre controversa, pois as empresas são entidades heterogêneas e os seus resultados são derivados do seu processo decisório, assim como aguardado, todas as variáveis não apresentaram normalidade pelo teste Jarque-Bera, mesmo empregando procedimentos de transformação das variáveis como padronização e uso do logaritmo natural nos valores originais. Decidiu-se, então, pela não exclusão de empresas com comportamentos diferenciado em relação à média amostral. Em adição, verificou-se a presença de outliers, sendo estes considerados valores superiores ou inferiores a três desvios padrões em relação à média. Observou-se a presença de 13 outliers e estes foram substituídos pela média da respectiva empresa no intervalo de tempo estudado. A decisão pela substituição pela média desses 13 valores atípicos ocorreu após avaliação individual de cada um deles, quando se constatou que se referiam a valores não distintos das séries históricas das empresas, sendo que os 13 dados ocorreram após processos de fusão/incorporação de empresas cuja reorganização societária trouxe as variações atípicas. Essa análise qualitativa de cada valor e a decisão por substituir pela média tem amparo no Hair Jr. et. al. (2015).

A matriz de correlação entre as variáveis de folga financeira e investimento em inovação encontra-se na Tabela 2.

Tabela 2 - Coeficientes de Correlação

\begin{tabular}{c|c|c|c|c|c|c|c|c|c|c|c}
\hline INOV & LIQU & TES & OVERTR & MA & MM & RET & CJ & EC & CC & RECEITA & \\
\hline 1,00 & $-0,0882$ & $-0,0882$ & $-0,1756$ & 0,0323 & $-0,051$ & $-0,017$ & 0,045 & 0,085 & $-0,086$ & 0,005 & INOVA \\
\hline & 1,00 & 0,162 & 0,334 & $-0,128$ & $-0,014$ & 0,038 & $-0,089$ & $-0,054$ & 0,129 & $-0,042$ & LIQUIDEZ \\
\hline & & 1,00 & 0,668 & 0131 & $-0,327$ & 0,059 & $-0,242$ & $-0,028$ & 0,008 & 0,246 & TESOURA \\
\hline & & & 1,00 & $-0,370$ & $-0,027$ & 0,048 & $-0,456$ & 0,044 & 0,023 & 0,243 & OVERTRADING \\
\hline & & & & 1,00 & $-0,039$ & 0,110 & $-0,047$ & $-0,043$ & $-0,054$ & $-0,429$ & MA \\
\hline & & & & & 1,00 & $-0,003$ & $-0,008$ & 0,039 & 0,029 & $-0,172$ & MM \\
\hline & & & & & & 1,00 & $-0,067$ & $-0,004$ & 0,011 & $-0,016$ & RETENCAO \\
\hline & & & & & & & 1,00 & $-0,136$ & $-0,041$ & $-0,044$ & CJ \\
\hline & & & & & & & & 1,00 & $-0,134$ & 0,076 & EC \\
\hline
\end{tabular}

Fonte: Elaborado pelos autores (2018).

Nota-se que nenhuma das variáveis apresentaram coeficiente de correlação superior a 0,5 , o que pode atenuar efeitos de multicolinearidade. A multicolinearidade está associada à correlação das variáveis independentes e ocorre quando existe duas ou mais variável independente no modelo explicando o mesmo efeito (CORRAR; PAULO; DIAS FILHO, 2012). Verifica-se que a maioria das variáveis não apresentam altos coeficientes de correlação, exceto a Margem Administrativa (MA) com as variáveis que envolvem e identificam o Coeficiente de Efeito Tesoura e o Coeficiente de Overtrading. Estes dados concordam parcialmente com os resultados de Bradley, Shepherd, \& Wiklund (2011) que também evidenciaram menor proximidade da folga potencial com a inovação, porém, não se identifica aqui associação da folga disponível com a inovação. 
A correlação entre as variáveis de folga financeira demonstra que não há sobreposição das variáveis e que as dimensões relativas ao disponível, recuperável e potencial são distintas.

No entanto, a matriz de correlação não é capaz de identificar a influência das variáveis de folga financeira nos investimentos em inovação. Por isso, o uso do modelo de regressão com dados em painel balanceado, conforme a equação 12 .

Inicialmente o modelo empírico proposto com os dados originais e efeito fixo apresentou a presença de heteroscedasticidade, que significa a presença de variânicas não homogênea, o que é natural quando se utiliza empresas com diferentes tamanhos e estratégias. Para minimizar o efeito da ausência de homocedasticidade, empregou-se a técnica de Mínimos Quadrados Ponderados (PINDYCK; RUBINFELD, 2004). A homocedasticidade está associada a dispersão do conjunto de resíduos, ou seja, a homocedasticidade é a caracteriza a dispersão homogênea dos resíduos das observações (CORRAR, PAULO; DIAS FILHO, 2012). Os resultados desta regressão estão expressos na Tabela 3.

Tabela 3 - Resultados da Regressão com Painel de Dados

\begin{tabular}{l|c|c|c|c}
\hline \multicolumn{1}{c|}{ Variáveis } & Coeficiente & Erro Padrão & razão-t & p-valor \\
\hline Const & 0,104831 & 0,135297 & 0,7748 & 0,4389 \\
\hline LIQUIDEZ & $-0,00908028$ & 0,0116215 & $-0,7813$ & 0,4351 \\
\hline TESOURA & 0,0349194 & 0,0155551 & 2,245 & $0,0253^{* *}$ \\
\hline OVERTRADING & $-0,118197$ & 0,0240443 & $-4,916$ & $0,0001^{* * *}$ \\
\hline MA & $-0,0646890$ & 0,0270357 & $-2,393$ & $0,0172^{* *}$ \\
\hline RETENCAO & $-0,0729751$ & 0,0882079 & $-0,8273$ & 0,4086 \\
\hline CJ & 0,000119770 & 0,000262363 & 0,4565 & 0,6483 \\
\hline CC & $-0,00326844$ & 0,00185942 & $-1,758$ & $0,0796^{*}$ \\
\hline RECEITA & 0,0235905 & 0,00980320 & 2,406 & $0,0166^{* *}$ \\
\hline
\end{tabular}

Notas: “***” confiança >99\%; “**” confiança $>95 \%$; “*” confiança $>90 \%$.

Variável dependente: Inovação

Fonte: Elaborado pelos autores (2018).

A estatística F $(10,386)$ do modelo apresenta o resultado de 13,501 com p-valor de 0,000, inferior ao limite de $5 \%$ o que permite aceitar a especificação do modelo (GUJARATI, 2006). O R ${ }^{2}$ foi de $25,91 \%$ o que é um representativo para esse estudo; ressalta-se que este é um percentual de explicação esperado, pois a decisão de investir em inovação é influenciada por outros fatores e não apenas a folga financeira (LEE, 2015; LEE; WU; PAO, 2014). Em adição, as correlações observadas entre as variáveis explicativas e a dependente corroboram o $\mathrm{R}^{2}$ ajustado em $23,99 \%$.

Percebe-se, na Tabela 3, que as significâncias das variáveis em relação à inovação apresentam resultados mistos. Todas as variáveis de folga financeira disponível mostram-se significativas na explicação do investimento em inovação, com exceção do índice de liquidez.

Os intervalos de confiança dos coeficientes significativos são apresentados na Tabela 4 com o interesse de avaliar a total dimensão de influência dessas variáveis nos investimentos em inovação.

Tabela 4 - Intervalo de Confiança dos Coeficientes Significativos

\begin{tabular}{c|c|c}
\hline Variável & Coeficiente & Intervalo de confiança de 95\% \\
\hline Const & 0,104831 & $(-0,161181 ; 0,370843)$ \\
\hline LIQUIDEZ & $-0,00908028$ & $(-0,0319297 ; 0,0137692)$ \\
\hline TESOURA & 0,0349194 & $(0,00433617 ; 0,0655026)$ \\
\hline OVERTRADING & $-0,118197$ & $(-0,165471 ;-0,0709226)$ \\
\hline MM & $-0,0646890$ & $(-0,117845 ;-0,0115333)$ \\
\hline
\end{tabular}


Santos, Guevara e Rodrigues (2018)

Folga Financeira e Inovação Empresarial no Brasil

\begin{tabular}{c|c|c}
\hline MA & $-0,0729751$ & $(-0,246403 ; 0,100453)$ \\
\hline RETENÇÃO & 0,000119770 & $(-0,000396070 ; 0,000635609)$ \\
\hline CJ & $-0,00326844$ & $(-0,00692429 ; 0,000387416)$ \\
\hline EC & 0,0235905 & $(0,00431614 ; 0,0428648)$ \\
\hline CC & $-0,00926958$ & $(-0,0176832 ;-0,000855999)$ \\
\hline RECEITA & 0,0154417 & $(-0,000908742 ; 0,0317922)$ \\
\hline
\end{tabular}

Fonte: Elaborado pelos autores (2018).

Nota-se que os intervalos de confiança alcançam os limites inferiores e superiores nas dimensões negativas e positivas e com elevada amplitude o que limita a análise da direção do impacto dos coeficientes nos investimentos em inovação, sendo possível, inclusive que os efeitos não sejam lineares como pressupõe o modelo empírico proposto, mas como assinala Lee (2015) a relação entre inovação e folga financeira pode ser não linear com formato de " $U$ " invertido.

No entanto, a amplitude dos coeficientes associada com os resultados descritivos pode sugerir que existem diferenças nesta relação em função de características das empresas, como por exemplo: tamanho (GEIGER; CASHEN, 2003), idade (LEE, 2015), setores e principalmente em relação as suas estratégias de inovação que são distintas (LEE; WU; PAO, 2014).

Em que pese as limitações na análise dos estimadores do modelo empírico, que particularmente, também refletem as informações disponibilizadas pelas empresas em seus relatórios de gestão e notas explicativas, ressalta-se que os resultados obtidos proporcionam uma análise complementar para a realidade brasileira referente aos estudos internacionais (GEIGER; CASHEN, 2003; ZONA, 2012; LEE; WU; PAO, 2014; LEE, 2015; ASHWIN; KRISHNAN; GEORGE, 2016).

Os coeficientes de Liquidez Corrente são negativos e, apesar dos intervalos de confiança se estenderem até o limite superior positivo, pode-se afirmar que as medianas se encontram no espaço negativo, sendo assim, as empresas que mais investem em inovação são aquelas com menores níveis de folga financeira disponível, tanto pelo saldo de tesouraria quanto pela liquidez corrente.

$\mathrm{O}$ fato do coeficiente Overtrading ser negativo enseja o entendimento de que as empresas da amostra que mais investem em inovação são aquelas que operam com baixo nível de folga financeira, porém valorizam o equilíbrio financeiro de curto prazo. Esse resultado ocorre quando as empresas decidem financiar adequadamente o ciclo operacional com fontes de longo prazo, mantendo os empréstimos e financiamentos inferiores aos recursos não cíclicos no ativo circulante (caixa e aplicações) (MATIAS, 2007).Lungeanu, Stern e Zajac (2016) apontam que a folga financeira pode gerar piores resultados de inovação, por isso, as empresas adotariam diferentes estratégias de inovação em função da sua folga financeira.

O excesso de folga financeira disponível não é interpretado pelas empresas brasileiras como uma vantagem, mas como um desperdício; o que pode também ser influenciado pelo elevado custo de capital no Brasil no período analisado, bem como as limitações existentes no mercado de crédito e capitais decorrentes dos reflexos da crise financeira de 2008/2009 (BARBA; CERETTA; VIEIRA, 2011) .

Essas evidências contrariam os resultados de Kuny, Basso e Kimura (2009) que assinalam que a folga financeira é uma estratégia de inovação para as empresas brasileiras entre 2002 e 2006, além das diferenças entre períodos e amostras, ressalta-se que o modelo 
empírico utilizado pelos autores foi distinto desse, quando utilizaram a folga como variável dependente. Por isso, entendemos que os resultados deste estudo trazem novas informações sobre os fatores determinantes da inovação.

Para as empresas analisadas o índice Margem Mercadológica (MM) apresenta coeficiente médio negativo, porém é a variável que apresenta a maior amplitude de resultados o que torna evidente que não há uma influência predominante, o que pode ser explicado pela diversidade de setores que compreendem as 100 maiores empresas do país.

Por outro lado, este resultado demonstra a importância desta folga financeira recuperável para os investimentos em inovação das empresas, de modo que esta pode influenciar positivamente ou negativamente. Torna-se importante essa discussão, pois os resultados de Geiger e Cashen (2003) apontaram para um efeito positivo da folga recuperável sobre a inovação, porém os autores agregaram os dados administrativos com os de marketing, de modo que a segregação, proposta aqui evidenciou o impacto, apenas da variável mercadológica.

A folga financeira potencial não se mostra significativa para os investimentos em inovação, ao contrário de Geiger e Cashen (2003) cujo resultado expressa um impacto negativo, considerando as variáveis utilizadas os autores sugerem que o maior nível de endividamento e comprometimento do fluxo de caixa influnencia de forma restritiva os investimentos em inovação. Resultado semelhante foi encontrado por Kuny, Basso e Kimura (2009) que apontam para uma preferência pelo uso do capital próprio para os investimentos em inovação.

Todavia, os resultados para esta amostra não confirmam a importância para o volume dos investimentos em inovação a folga financeira potencial, o que pode, também estar associado ao período analisado.

\section{CONCLUSÕES E CONSIDERAÇÕES FINAIS}

O presente trabalho teve como objetivo analisar a influência dos diferentes níveis de folga financeira nos investimentos em inovação das 100 maiores empresas não financeiras listadas na B3, a partir de um modelo empírico exploratório, em especial, para a realidade brasileira.

Três conclusões podem ser propostas a partir dos resultados deste estudo: a) A folga financeira se apresenta em diferentes dimensões e por isso, o tratamento metodológico e a escolha pontual de determinadas variáveis precisam reconhecer a abrangência de escopo de cada indicador ou usar todos; b) A folga financeira disponível é àquela que mais exerce influência nos investimentos em inovação, considerando as empresas da amostra; c) Não há um efeito linear ou único da folga financeira nos investimentos em inovação para todo o tipo de empresa.

A partir desses resultados, implicações teóricas e empresariais podem ser consideradas como contribuições na tentativa de aumentar a compreensão sobre a relação entre folga financeira e investimentos em inovação, assim como, auxiliar na proposição de novos estudos.

Um resultado chamou atenção por apresentar uma relação negativa com a variável inovação. O Overtrading, a qual esperava-se uma relação positiva, uma vez que maior volume de recursos circulante líquido contribuísse para investimentos em inovação. Contudo, Stern e Zajac (2016) apontam que a folga financeira pode gerar piores resultados de inovação, o que 
indica que as empresas da amostra que mais investem em inovação são aquelas que operam com baixo nível de folga financeira.

Os efeitos da folga financeira nos investimentos em inovação devem considerar os problemas de agência relativos ao uso dos excedentes de recursos da empresa. Apesar da corrente majoritária dos resultados assinalar para o efeito positivo da folga nos investimentos em inovação, os resultados deste estudo mostram que isto pode não ocorrer para as empresas brasileiras. Neste sentido, seria interessante para trabalhos posteriores moderar os efeitos da folga em função do perfil de gestão e do corpo diretivo da empresa. Não obstante, controlar variáveis macroeconômicas quanto a liquidez no mercado de crédito e políticas de fomento à inovação em diferentes períodos, podem contribuir no melhor entendimento no uso da folga financeira.

O uso da folga financeira também pode ser estatisticamente distinta entre empresas de diferentes setores e com diferentes estratégias de negócio, nesta direção, estudos qualitativos de casos múltiplos ou mesmo quantitativos que consigam, em larga escala, indicadores que mensurem essas variáveis podem avaliar como a folga financeira impacta os investimentos em inovação. A discrepância de resultados descritivos das 100 maiores empresas brasileiras sugere que as estratégias de inovação não são tratadas de igual forma.

A necessidade de investimentos em inovação exige das empresas um planejamento financeiro mais robusto e a folga financeira é fundamental para a exequibilidade no longo prazo dos projetos de investimento. Desta forma, os gestores devem zelar pelo equilíbrio financeiro das empresas, porém os investimentos em inovação não podem ocorrer somente com excedente de recursos, pois o excesso de precaução pode ocasionar em perdas de oportunidade.

Enquanto recurso estratégico, os investimentos em inovação precisam ser apresentados com maior e melhor qualidade nas demonstrações financeiras das empresas ou nos seus planos de negócios. No processo dessa pesquisa, foi possível notar para o universo das 100 maiores empresas da B3 que poucas têm o cuidado de apresentar e informar aos stakeholders os seus gastos em inovação; ainda que muitas informem esses resultados para o IBGE na Pesquisa de Inovação Tecnológica, os dados para o público em geral não são disponibilizados ao nível da firma, de sorte que, somente através da evidenciação contábil é possível identificar os esforços em inovação realizados pelas empresas.

Por isso, novos estudos podem avançar nessa discussão ao analisar o efeito percebido entre os stakeholders com a presença de maiores e melhores níveis de informação quanto aos investimentos em inovação e as características financeiras da empresa para garantir o investimento no longo prazo.

\section{REFERÊNCIAS}

ARAÚJO, J. G.; CONFESSOR, K. L. A.; SANTOS, J. F. dos; OLIVEIRA, M. R. G. de; PRAZERES, R. V. dos. A Estrutura de Capital e a Governança: Análise dos conselhos de Admnistração e Estrutura de Propriedade nas empresas listadas no IBRX-100. Revista Gestão, Finanças e Contabilidade, v. 7, n. 2, p. 121-140, 2017.

ASHWIN, A. S.; KRISHNAN, R. T.; GEORGE, R. Board Characteristics, Financial Slack and R\&D Investments. International Studies of Management \& Organization, v. 46, n. 1, p. 8-23, 2016. 
BARBA, F. G. D.; CERETTA, P. S.; VIEIRA, K. M. Modelagem da Volatilidade em Períodos de Crise: Análise das Distribuições Alternativas no BRICS e nos EUA. Revista de Gestão, v. 18, n. 4, p. 569-584, 2011.

BEUREN, I. M.; STAROSKY FILHO, L.; KRESPI, N. T. Organizational slack versus financial performance. A study of companies on BM\&FBovespa. Contaduría y Administración, v. 59, n. 2, p. 145-177, 2014.

BILLETT, M. T.; GARFINKEL, J. A. Financial Flexibility and the Cost of External Finance for U.S. Bank Holding Companies. Journal of Money, Credit and Banking, v. 36, n. 5, p. 827-852, 2004.

BOURGEOIS, L. J. On the measurement of organizational slack. The Academy of Management Review, v. 6, n. 1, p. 29-39, 1981.

BRADLEY, S. W.; SHEPHERD, D. A.; WIKLUND, J. The Importance of Slack for New Organizations Facing 'Tough' Environments. Journal of Management Studies, v. 48, n. 5, p. 1071-109, 2011.

CAMPOS, A. L. S.; NAKAMURA, W. T. Folga Financeira Avaliada como Endividamento Relativo e Estrutura de Capital. Revista de Finanças Aplicadas, v. 1, p. 1-19, 2013.

CHEVARRIA, D. G.; CARLIN, D. D. O. Investigação da Relação Entre a Estrutura de Capital e Inovação e Intensidade Tecnológica nas Companhias Abertas Brasileiras: Uma Análise com Base na Taxonomia de Pavitt. In: SIMPÓSIO DE GESTÃO DA INOVAÇÃO TECNOLÓGICA. 3, 2012. Anais... Salvador: ANPAD. 2012. p. 1-15.

CONNELLY, J. T. Investment policy at family firms: Evidence from Thailand. Journal of Economics and Business, v. 83, p. 91-122, 2016.

CORRAR, L. J.; PAULO, E.; DIAS FILHO, J. M. (Coord). Análise Multivariada: para os cursos de administração, ciências contábeis e economia. São Paulo: Atlas, 2012.

CYERT, R. M.; MARCH, J. G. A Behavioral Theory of the Firm. New Jersey: Prentice Hall, 1963.

DALLABONA, L. F.; MACOHON. E. R.; ZITTEI, M.; LAVARDA, C. E. F. Antecedentes e efeitos de folga organizacionalem empresas listadas na BM\&FBOVESPA: Análise sob as perspectivas contingencial e agência. In: ENCONTRO DA ANPAD - ENANPAD, 37, 2013. Anais... Rio de Janeiro: ANPAD. 2013. p. 1-16.

DANIEL, F.; LOHRKE, F. T.; FORNACIARI, C. J.; TURNER Jr. R. A. Slack resources and firm performance: a meta-analysis. Journal of Business Research, v. 57, n. 6, p. 565-574, 2004. 
FARIA, J. A. de; SILVA, S. M. G. de. The effects of information asymmetry on budget slack: An experimental research. African Journal of Busyness Management, v. 7, n. 13, p. 10861099, 2013.

FRANQUESA, J.; BRANDYBERRY, A. Organizational Slack and Information Technology Innovation Adoption in SMEs. International Journal of e-Business Research, v. 5, n. 1, p. 25-48, 2009.

GEIGER, S. W.; CASHEN, L. H. A Multidimensional Examination of Slack and Its Impact on Innovation. Jornal of Managerial Issues, v. 14, n. 1, p. 68-84, 2003.

GOMES, G.; MACHADO, D. D. P.; GIOTTO, O. T. O Que se Produz de Conhecimento Sobre Inovação? Uma Breve Análise das Características dos Artigos de Inovação Publicados nos Anais do EnANPAD (1997-2009). Revista de Ciências da Administração, v. 11, n. 25, p. 209-228, 2009.

GUJARATI, D. Econometria Básica. São Paulo: Campus, 2006.

HAIR Jr., et al. Análise Multivariada de Dados. 5a ed. Porto Alegre: Bookman, 2005.

KUNIY, M.; BASSO, L. F. C.; KIMURA, H. Estratégias de Inovação e Estrutura de Capital de Empresas Brasileiras. In: SIMPÓSIO DE ADMINISTRAÇÃO DA PRODUÇÃO, LOGÍSTICA E OPERAÇÕES INTERNACIONAIS, 12, 2009. Anais... São Paulo: FGV. 2009. p. 1-16.

LAI, H.-C. When is betweenness centrality useful to firms pursuing technological diversity? An internal resources view. Technology Analysis \& Strategic Management, v. 28, n. 5, p. 507-523, 2016.

LATHAM, S.; BRAUN, M. Managerial Risk, Innovation, and Organizational Decline. Journal of Management, v. 35, n. 2, p. 258-281, 2009.

LEE, C.-Y.; WU, H.-L.; PAO, H.-W. How does R\&D intensity influence firm explorativeness? Evidence of R\&D active firms in four advanced countries. Technovation, v. 34, n. 10, p. 582-593, 2014.

LEE, S. Slack and innovation: Investigating the relationship in Korea. Journal of Business Research, v. 68, n. 9, p. 1895 - 1905, 2015.

LINTNER, J. Distribution of Incomes of Corporations among Dividends, Retained Earnings and Taxes. The American Economic Review, p. 97-113, 1956.

LUNGEANU, R.; STERN, I.; ZAJAC, E. J. When do firms change technology-sourcing vehicles? the role of poor innovative performance and financial slack. Strategic Management Journal, v. 37, n. 5, p. 855-869, 2016. 
Folga Financeira e Inovação Empresarial no Brasil

MATIAS, A. B. (Coord.) Finanças Corporativas de Curto Prazo. A Gestão do Valor do Capital de Giro. São Paulo: Atlas, 2007.

MOSES, D. O. Organizational slack and risk-taking behavior: tests of product pricing strategy. Journal of Organizational Change Management, v. 5, n. 3, p. 38-54, 1992.

NATIVIDAD, G. Financial Slack, Strategy, and Competition in Movie Distribution. Organization Science, v. 24, n. 3, p. 846-864, 2013.

NOHRIA, N.; GULATI, R. Is slack good or bad for innovation? The Academy of Management Journal, v. 39, n. 5, p. 1245-1264, 1996.

OLIVEIRA, G. R. de; DALLABONA, L. F.; PLETSCH, C. S. Perfil Bibliométrico da Produção Científica sobre Folga Organizacional em Periódicos Nacionais. Desafio Online, v. 6, n. 2, p. 255-277, 2018.

PINDYCK, R. S.; RUBINFELD, D. L. Econometria: Modelos e Previsões. Rio de Janeiro: Elsevier, 2004.

PONTE, V. M. R.; OLIVEIRA, M. C. Prática da evidenciação de informações avançadas e não obrgatórias nas demonstrações contábeis das empresas brasileiras. Revista

Contabilidade \& Financas, v. 15, n. 36, p.7-20, 2004.

SANGHOON, L. Slack and innovation: Investigating the relationship in Korea. Journal of Business Research, v. 68, n. 9, p. 1895-1905, 2015.

SANTOS, D. F. L. BASSO, L. F. C.; KIMURA, H. Innovation efforts and performances of Brazilian firms. Journal of Business Research, v. 67, n. 4, p. 527-535, 2014.

SANTOS, D. F. L.; BASSO, L. F. C.; KIMURA, H. A Estrutura da Capacidade de Inovar das Empresas Brasileiras: Uma Proposta de Construto. Revista de Administração e Inovação, v. 9, n. 3, p. 103-128, 2012.

SANTOS, V. D. Percepção de justiça na avaliação de desempenho versus folga organizacional dos controllers: Um estudo em empresas com sistemas de remuneração por recompensa. 169f. 2010. Dissertação (Mestrado em Ciências Contábeis) - Universidade Regional de Blumenau, Blumenau, 2010.

SATTA, G.; PAROLA, F.; PENCO, L. ; FALCO, S. E. Insights to technological alliances and financial resources as antecedents of high-tech firms' innovative performance. R\&D

Management, v. 46, Special Issue, p. 127-147, 2016.

VANACKER, T.; COLLEWAERT, V.; PAELEMAN, I. The relationship between slack resources and the performance of entrepreneurial firms: The role of centure capital and angel investors. Journal of Management Studies, v. 5, n. 6, p. 1070-1096, 2013. 
Folga Financeira e Inovação Empresarial no Brasil

WANG, C.; LUO, B.; LIU, Y.; WEI, Z. The impact of executives perceptions of envionmental theats and organizational slack on innovation strategies. Nankai Business Review International, v. 7, n. 2, p. 216-230, 2016.

WANG, H. et al. Slack Resources and the Rent-Generating Potential of Firm-Specific Knowledge. Journal of Management, v. 42, n. 2, p. 500-523, 2016.

ZONA, F. Corporate Investing as a Response to Economic Downturn: Prospect Theory, the Behavioural Agency Model and the Role of Financial Slack. British Journal of Management, v. 23, Issue Supplement, p. 42-57, 2012. 
Santos, Guevara e Rodrigues (2018)

Folga Financeira e Inovação Empresarial no Brasil

\section{APÊNDICE A}

Quadro 3 - Empresas utilizadas no estudo

\begin{tabular}{|c|c|c|}
\hline AMBEV S/A & CYRELA REALT & IOCHP-MAXION \\
\hline PETROBRAS & ENERGIAS BR & VALID \\
\hline JBS & FIBRIA & COPASA \\
\hline KROTON & QUALICORP & EZTEC \\
\hline VALE & EVEN & SAO MARTINHO \\
\hline CCR AS & TRACTEBEL & ANIMA \\
\hline GERDAU & ECORODOVIAS & SER EDUCA \\
\hline BRF AS & RAIADROGASIL & M.DIASBRANCO \\
\hline TIM PART S/A & EQUATORIAL & CLARO TELECOM PART S/A \\
\hline CIELO & CESP & ITAUSA \\
\hline CEMIG & NATURA & INVEPAR \\
\hline EMBRAER & RUMO LOG & NEOENERGIA \\
\hline LOJAS RENNER & LOJAS AMERIC & SANTO ANTONIO ENERGIA AS \\
\hline SID NACIONAL & P.ACUCAR-CBD & RAIZEN ENERGIA AS \\
\hline WEG & RANDON PART & DUFRY AG \\
\hline ULTRAPAR & COSAN & ENERGISA \\
\hline MARCOPOLO & LOCALIZA & CIA BRASILIANA DE ENERGIA \\
\hline KLABIN S/A & TOTVS & $\begin{array}{c}\text { CONC DO AEROP INTER DE } \\
\text { GUARULHOS S/A }\end{array}$ \\
\hline USIMINAS & MINERVA & PDG REALT \\
\hline TELEF BRASIL & VIAVAREJO & $\begin{array}{l}\text { CIA HIDRO ELETRICA SÃO } \\
\text { FRANCISCO }\end{array}$ \\
\hline SUZANO PAPEL & CIA HERING & $\begin{array}{l}\text { CEDAE- CIA ESTADUAL DE } \\
\text { AGUAS E ESGOTOS }\end{array}$ \\
\hline BR MALLS PAR & AES TIETE & TEREOS \\
\hline $\mathrm{OI}$ & TAESA & REDE ENERGIA \\
\hline HYPERMARCAS & B2W DIGITAL & ARTERIS \\
\hline GAFISA & GOL & MENDES JR \\
\hline MARFRIG & COPEL & ALUPAR \\
\hline SABESP & LIGHT S/A & $\begin{array}{l}\text { ELDORADO BRASIL } \\
\text { CELULOSE S/A }\end{array}$ \\
\hline CPFL ENERGIA & TRAN PAULIST & BIOSEV \\
\hline ESTACIO PART & ELETROPAULO & COMGAS \\
\hline MRV & IGUATEMI & SANEPAR \\
\hline ODONTOPREV & MILLS & JSL \\
\hline ELETROBRAS & MULTIPLAN & ENEVA \\
\hline BRASKEM & ROSSI RESID & \\
\hline DURATEX & QGEP PART & \\
\hline
\end{tabular}

Fonte: Elaborado pelos autores (2018). 